Orehek, E., Forest, A. L., \& Barbaro, N. (2018). A people-as-means approach to interpersonal relationships. Perspectives on Psychological Science, 13, 373-389.

Final Published version of this paper is available here:

http://journals.sagepub.com/doi/abs/10.1177/1745691617744522

A People-As-Means Approach to Interpersonal Relationships

Edward Orehek

Amanda L. Forest

University of Pittsburgh

Nicole Barbaro

Oakland University 


\begin{abstract}
Interpersonal relationships and goal pursuit are intimately interconnected. In the present paper, we present a people-as-means perspective on relationships. According to this perspective, people serve as means to goals-helping other people to reach their goals in a variety of ways, such as by contributing their time, lending their knowledge, skills, and resources, and providing emotional support and encouragement. Because people serve as means to goals, we propose that considering relationship processes in terms of the principles of goal pursuit can provide novel and important insights into the ways that people think, feel, and behave in these interpersonal contexts. We describe the principles of means-goals relations, review evidence for each principle involving people as means, and discuss implications of our approach for relationship formation, maintenance, and dissolution.
\end{abstract}

Keywords: goals; means; instrumentality; interpersonal relationships; relationship formation; relationship maintenance; relationship dissolution 


\section{A People-As-Means Approach to Interpersonal Relationships}

From birth through adulthood, interpersonal relationships are shaped by the way partners support one another's goal pursuit. Infants form social bonds with caregivers who meet their needs for food, comfort, and safety. Adolescents develop social ties with their peer group, teachers, and coaches who provide companionship, guidance, and advice. Adults establish social connections with romantic partners and friends who support them as they pursue personal and interpersonal goals, and develop relationships with professors, colleagues, and mentors who facilitate academic and professional goals, among others. Throughout the lifespan then, people construct relationships with others who facilitate their progress toward goals. By facilitating progress toward goals, relationship partners serve as means to those goals. What implications does recognizing that partners serve as means to goals have for evaluations of those partners, and for relationship processes? In the pages that follow, we present a people-as-means approach to interpersonal relationships, summarize evidence linking principles of goal pursuit to instances in which people are means, and discuss the novel insights gained from adopting a people-as meansperspective on relationships.

\section{Theoretical Overview}

Goal systems theory (Kruglanski et al., 2002) serves as the foundation from which our perspective grows. It outlines the principles of means-goal relations and is assumed to apply to all goal contents and all means by which they are pursued. Goal systems theory was not developed to explain close relationships, and did not originally consider people as means to goals. However, much research has implicitly or explicitly investigated the implications of considering people as means to goals. 
Goal systems theory can be summarized according to eight principles, as shown in Figure 1. Here, we outline the principles and consider how they apply to cases in which people serve as means.

\section{Principle 1. Top-Down Activation of Means by Goals}

When a person has an important goal in mind, s/he directs attention toward means of attainment so that goal pursuit can be initiated. Means that have proven instrumental in past pursuits are most likely to be brought to mind and used in the future (Aarts \& Dijksterhuis, 2000b; Custers, Eitam, \& Bargh, 2012; Danner, Aarts, \& de Vries, 2007; Sheeran et al., 2005). Thus, as people move through their various pursuits during a day, they should think of and attend to people who are useful to their current concerns. For example, sociability and achievement goals (vs. control) bring to mind people who are instrumental to that goal (Fitzsimons \& Shah, 2008). The goal to have sex increases attention directed toward potential sexual partners (Maner et al., 2007). Threats of failure, death, or separation lead people to bring to mind attachment figures who serve as support providers (Cox, Arndt, Pyszczynski, Greenberg, Abdollahi, \& Solomon, 2008; Mikulincer, Gillath, \& Shaver, 2002). Thus, as people pursue their goals, they mentally summon the people who are integral to goal attainment.

\section{Principle 2. Affective Transfer}

Means are evaluated according to their perceived instrumentality to the goals of the moment (Fishbach, Shah, \& Kruglanski, 2004). When partners serve as means to a person's goals, the person evaluates those instrumental partners positively. For example, people report wanting to spend more time with potential new friends who are instrumental (vs. noninstrumental) to their current (academic achievement or fitness) goal (Slotter \& Gardner, 2011). People feel interpersonally closer to an instrumental partner than a non-instrumental partner 
(Fitzsimons \& Fishbach, 2010; Fitzsimons \& Shah, 2008; Gomillion \& Murray, 2014). People feel more gratitude and closeness to a helper when the task with which the helper is assisting is still in progress, as compared to when the task had been completed (i.e., gratitude is greater when the helper is still instrumental; Converse \& Fishbach, 2012; Fitzsimons \& Fishbach, 2010). Thus, partners are evaluated more positively when they are instrumental to current goals.

\section{Principle 3. "Bottom-up" Activation of Goals by Means}

Available means signal an opportunity for goal pursuit and bring to mind associated goals (Shah, Hall, \& Leander, 2009; Shah, 2005; Shah \& Kruglanski, 2003). The real or imagined presence of a person should therefore bring to mind associated goals. Indeed, exposure to a role model can increase hard work and inspiration for shared goals (Aarts, Gollwitzer, \& Hassin, 2004; Lockwood \& Kunda, 1997). A reminder of a partner increases commitment to associated goals (Shah, 2003), adoption of associated goal pursuit strategies (Orehek, Vazeou-Nieuwenhuis, Quick, \& Weaverling, 2017), motivation to engage in goal-relevant behaviors (Leander, Shah, \& Chartrand, 2009), persistence in pursuit of associated goals (Shah, 2003; vanDellen \& Hoyle, 2010), and better performance on goal-relevant tasks (Fitzsimons \& Bargh, 2003). Just as goals can instigate a search for a person to serve as a means, the presence of a person who serves as a means can initiate goal pursuit afforded by the person.

\section{Principle 4. Multifinality}

Some means - referred to as multifinal means - can satisfy multiple goals simultaneously. For example, eating fruit is multifinal when it serves as a means to both taste and health (Orehek \& Vazeou-Nieuwenhuis, 2016). Multifinal means are evaluated more positively than unifinal means, which serve only one goal, because they can satisfy many goals, thus generating more value (Chun, Kruglanski, Sleeth-Keppler, \& Friedman, 2011; Kruglanski et al., 
2013; Orehek, Mauro, Kruglanski, \& van der Bles, 2012). However, multifinal means are not always easy to find and adopt. As the number of goals increases, the set of possible means that can satisfy all of them is reduced (Kopetz, Faber, Fishbach, \& Kruglanski, 2011). For example, finding a delicious meal is easy, but finding a delicious, healthy, convenient, and inexpensive meal can be difficult (Orehek \& Vazeou-Nieuwenhuis, 2016). Partners who serve multiple goals should be evaluated more positively than partners who serve only one goal. However, partners who serve multiple goals should also be less common - that is, more difficult to find - than partners who serve just a few goals. We have found in several studies that the more goals a person serves, the more favorably that person is evaluated on measures of interpersonal closeness, perceived social support, conversation quality, and perceived responsiveness (Orehek, Forest, \& Wingrove, 2017). In another study, multifinal job applicants were rated more favorably when evaluators held each of the goals the applicant served (Chun et al., 2011). In addition, we found that partners who are multifinal are less common in people's existing social networks (Orehek et al., 2017). This suggests that partners who are multifinal are less common in the population, and thus should be difficult to find. However, such people should also be uniquely appreciated.

\section{Principle 5. Dilution}

Multifinal means have the benefit of being able to satisfy multiple goals simultaneously, but come with the cost of decreased perceived instrumentality toward each goal (Zhang, Fishbach, \& Kruglanski, 2007; see also Orehek et al., 2012). This dilution effect occurs when a means serves multiple goals that are dissimilar or incompatible with one another, but is reduced or eliminated when a means serves multiple goals that are similar or compatible with one another (Zhang et al., 2007). Thus, the more goals a partner serves, the less instrumental s/he may be 
considered for each of those goals — at least when those goals are incompatible (Light \&

Fitzsimons, 2014). Preliminary evidence supports the notion that dilution can occur when people serve as means, and that similarity and complementarity of actions reduces the dilution effect (Myers, O’brien, Belota, \& Toyafuka 1984; Park, 1989; Smith, Adams, \& Schorr 1978; Smith, 1981). Importantly, the set of conditions that foster the dilution effects are often absent when evaluating close relationship partners. The more a person gets to know a partner, the better able that person should be to see the complementarity among their actions and goals to which the partner is instrumental. However, dilution may be more likely in early stages of impression formation or when abstract representations (such as online dating profiles or job resumes) guide evaluations (see Eastwick, Finkel, \& Eagly, 2011). Contrary to our expectations, some writers have suggested that dilution may occur frequently in close relationships (Finkel et al., 2014; Light \& Fitzsimons, 2014). Research is needed to investigate these possibilities.

\section{Principle 6. Resource Pulling}

People often have a number of goals and tasks in mind, and can become distracted when pursuing a focal task when alternative tasks pull attention away from and reduce commitment to it. Whether an alternative task pulls resources from the focal task is determined by compatibility of the two tasks. When an incompatible second task captures a person's attention, resources are pulled away, impeding pursuit of the focal task (Shah \& Kruglanski, 2002). When people serve as means, a similar process would occur if an alternative partner pulls attention and commitment away from a current partner. In one illustration of the pulling effect, the longer people in committed romantic relationships attended to pictures of attractive alternatives, the less satisfied, less committed, and less close they felt to their relationship partner (Miller, 1997). Attention to alternatives also predicted relationship termination eight weeks later. In another study, 
romantically attached individuals' satisfaction with their current relationship decreased following exposure to a high quality (vs. low quality) alternative (Kenrick, Neuberg, Zierk, \& Krones, 1994). Participants in another study who received feedback from an attractive alternative partner stating that they had potential as a dating partner felt less relationship commitment and satisfaction following the feedback (Kavanagh, Fletcher, \& Ellis, 2014). In contrast, romantically rejected participants were more committed and satisfied with their current partner following the feedback. The presence or perception that alternative partners are available is a predictor of divorce (South \& Lloyd 1995; South, Trent, \& Shen, 2001; Udry, 1981). Thus, the presence of alternative partners may produce decreased commitment to present partners, increasing the likelihood of romantic relationship dissolution.

\section{Principle 7. Shielding}

Resource pulling can be reduced by inhibiting thoughts of alternative tasks during focal task pursuit. Inhibition of alternatives, or shielding, occurs when one's level of commitment to the focal task is stronger than alternatives (Shah, Friedman, \& Kruglanski, 2002). In close relationships the shielding principle translates into what we call relationship shielding. When a person is strongly committed to a romantic partner, then alternative partners are devalued and attention is directed away from them, thus protecting, or shielding, the current relationship from threats. People in a romantic relationship rate alternative partners as less attractive than do single participants (Karremans, Dotch, \& Corneille, 2011; Miller \& Maner, 2010; Simpson, Gangestad, \& Lerma, 1990). This effect is especially pronounced for people who are strongly (vs. weakly) satisfied with or committed to their current partner (Cole, Trope, \& Balcetis, 2016; Johnson \& Rusbult, 1989; Lydon et al., 1999; Lydon, Fitzsimons, \& Naidoo, 2003; see also Meyer, Berkman, Karremans, \& Lieberman, 2011). Another series of studies has demonstrated that 
people committed to their partner direct attention away from attractive alternatives (Linardatos \& Lydon, 2011; Maner, Gailliot, \& Miller, 2009).

Another strategy for shielding one's relationship from potential threats would be to make oneself seem less desirable to potentially-interested others. Engaging in risky behavior is one way in which men try to stand out to potential partners. After interacting with an available (vs. unavailable) woman, single men displayed more risk-taking behavior if the available woman was going to see their performance (Baker \& Maner, 2009). No effects were found when performance was private. This pattern of results was replicated in another study, which also found that committed men became less risky under the same conditions in which single men became riskier (Frankenhuis \& Karremans, 2012), suggesting that men in committed romantic relationships protect their relationship by appearing less attractive to potential partners. Recent research has found that women who are low in commitment to a relationship partner tend to dress more attractively when expecting to meet a single man than an unavailable man, but women committed to their relationships do not show this effect (Forest, Krueger, \& Orehek, 2017). These studies show that people engage in a variety of relationship shielding tactics: They devalue and direct their attention away from attractive alternatives and make themselves appear less desirable to alternative partners.

\section{Principle 8. Means Substitution}

More than one means is often available to attain a goal (Kruglanski et al., 2011). Means are substitutable for one another when they are each instrumental ways of attaining a goal (Lewin, 1935; Kruglanski et al., 2002). The strength of a person's preference for one means over another depends on the perceived instrumentality of each for the goal. In romantic relationships, partner substitution occurs when one permanently leaves a current partner for an alternative 
partner (i.e., mate switching; Buss, Goetz, Duntley, Asao, \& Conroy-Beam, 2017). Forty-three percent of men and $49 \%$ of women reported having engaged in such permanent romantic partner substitution at least once (Schmitt \& Buss, 2001). In cases in which a person does not leave the original relationship, but merely establishes a new short-term relationship, complete partner substitution would not be said to occur. The conditions under which partner substitution occurs should depend on the suitability of one's current partner in comparison to the suitability of alternative partners one can attract. Partner substitution should be more likely when one's current partner decreases in value, and/or a higher value partner is available.

Consistent with this principle, people in romantic relationships are more satisfied with their relationships when their current partner is perceived to be of higher quality than alternative partners in the local mating pool (Conroy-Beam, Goetz, \& Buss, 2016). As one's current partner decreases in perceived instrumentality, the likelihood of relationship dissolution increases (Fitzsimons, Finkel, \& Vandellen, 2015; Weisfeld \& Weisfeld, 2002). Infertility in relationships is associated with diminished relationship satisfaction (Leiblum, Aviv, \& Hamer, 1998; Millheiser, et al., 2010) and is predictive of divorce (Kjaer et al., 2014). Our people-as-means approach suggests one possible explanation for such effects: When a couple would like to have children, and are not successful in doing so, this likely leads to perceptions of the partner as noninstrumental in an important domain. When a person perceives a partner as less instrumental than s/he used to, or when alternatives who are more instrumental than the partner are available, then partner substitution becomes more likely.

\section{Summary}

Evidence involving instances in which people serve as means to goals provides strong support for most of the goal systems theory principles, which were developed considering 
objects or activities as means (not people). The principle with the greatest need for additional investigation is Principle 5, the dilution principle. Understanding whether, when, and why dilution operates (or does not) in contexts in which people serve as means to goals represents an important and exciting area for future research. Our people-as-means framework suggests that people evaluate others according to their perceived instrumentality, form and maintain relationships with partners they perceive to be instrumental to important goals, and dissolve relationships when a partner is no longer instrumental or when a more instrumental alternative is available. In addition, people find relationships most fulfilling or rewarding when they perceive their partner as instrumental. Principles 1-5 have been investigated among a variety of relationship types, including romantic relationships, friendships, and acquaintances. Principles 68 have mostly been investigated among romantic relationships. We expect these processes to extend to other relationship types. For example, a person may shield a relationship with a babysitter so that s/he is available when needed, feel less close and committed to that babysitter if a new one becomes available, and replace the babysitter with the new one if the new one proves more reliable. We next turn our attention to consideration of the person serving as the means, and propose a dyadic approach to people as means, highlighting implications that go beyond what can be gleaned from goal systems theory.

\section{Mutual Perceived Instrumentality}

One important way that people as means differ from the kinds of means that have been traditionally studied in the goals literature — objects or activities_-is that people have their own minds. Thus, whereas previous work involving non-people means has, logically, ignored the implications of goal pursuit principles for the means, turning our focus to people as means introduces the need and exciting opportunity to consider the implications of these principles for 
the person serving as the means. We suggest that people often like to serve as means to goals. They derive a sense of personal importance, esteem, competence, control, value, and belongingness from their ability to help others (Inagaki \& Orehek, 2017; Orehek, in press; Orehek \& Weaverling, 2017). Thus, people evaluate themselves in the same way they evaluate others: They evaluate themselves according to their perceived instrumentality to others. People should be motivated to form and maintain relationships with partners they can be instrumental toward, and to dissolve relationships when they can no longer be instrumental to their partner or when they find an alternative to whom they can be more instrumental. In addition, people should find relationships most fulfilling or rewarding when they perceive themselves as instrumental to their partner. These possibilities have not yet been empirically investigated, and warrant investigation.

When considering relationship partners as means to goals, it is important to take into account the contributions and perspectives of both partners and the processes that unfold across time. We propose that relationships are likely to thrive when partners experience mutual perceived instrumentality—when each person perceives the partner as instrumental to his or her important goals and perceives him/herself as instrumental to his or her partner's important goals (Orehek \& Forest, 2016). When such opportunities are absent, people may feel under-benefitted, unimportant, or unfulfilled. This emphasis on mutual perceived instrumentality leads to a number of novel predictions, which we present in the remaining sections of the paper.

We postulate that the value gained from serving as a means and the value gained from having another person serve as a means is additive. Thus, both having the opportunity to serve as a means for a partner and having a partner who is instrumental should contribute to strong 
relationship satisfaction. Having a partner with whom one is not able to be instrumental or who is not instrumental to one's own goals should reduce relationship satisfaction.

One might expect that relationships are maximally satisfying when the instrumentality that one gives to and receives from a partner are balanced, and that imbalances in instrumentality would result in conflict and dissatisfaction in one or both members of the dyad (Hatfield, \& Rapson, 2011; Hatfield, Walster, \& Berscheid, 1978). However, we postulate that apparent imbalances in instrumentality will not always be problematic, for at least three reasons. First, there are times in which a relationship may, at first glance, appear to be imbalanced, when in fact, mutual perceived instrumentality exists. For example, it may be obvious that a parent feeds, clothes, and cares for his/her child. It may be less obvious that the child provides the parent with a sense of social connection and generativity. Second, in close relationships, partners often track each other's needs even when there is no opportunity for reciprocation (Clark, Mills, \& Powell, 1986) and tend not to track one another's inputs into joint tasks (Clark, 1984; Clark, Mills, \& Corcoran, 1989). Thus, we suspect that temporary imbalances in instrumentality may sometimes go unnoticed in close relationships and, if noticed, may be tolerated insofar as the person who is disproportionately serving as a means feels that the partner would be concerned and responsive (and willing to serve as a means) if the person had a need arise (Clark \& Aragon, 2014). Third, even if partners have some awareness of an imbalance, the balance of instrumentality between relationship partners should be less important than the total value derived from having a partner serve as a means to one's goals and from serving as a means to that partner's goals; to the extent that a person gains utility through either or both of these avenues, s/he should feel positively about the relationship. 
Adopting a people-as-means perspective on relationships has important implications for understanding a variety of relationship processes. We outline these implications in the sections that follow and highlight some of the novel predictions that our perspective enables us to generate. First, we consider the perspective of the person serving as the means.

\section{Implications for the Person Serving as a Means}

We postulate that serving as an instrumental means is just as important as having instrumental others. Being instrumental to others should increase both the felt closeness to the person whom one has helped and increase one's own sense of self-worth. Serving as an instrumental means to other people provides benefits to the support provider and enhances the relationship between the support provider and recipient (Inagaki \& Orehek, 2017). For example, participants who performed a favor for someone they previously had a negative or neutral impression of came to like that person more (Jecker \& Landy, 1969). Giving affection to a romantic partner is associated with commitment to the relationship (Horan \& Booth-Butterfield, 2010). Giving support to others increases self-esteem (Piferi \& Lawler, 2006), self-worth (Gruenewald, Liao, \& Seeman, 2012), and felt social connection with that person (Inagaki \& Eisenberger, 2012). People who help others benefit most if they experience the choice to help as autonomous (Weinstein \& Ryan 2010; see also Williamson \& Clark, 1989; 1992). Thus, serving as an instrumental means is important to people: they want to feel valuable, useful, and helpful. Doing so allows them to feel close to their relationship partners and to experience a heightened sense of self-worth. Because serving as a means to others offers these benefits, people should be especially likely to offer to serve as a means to others' or to go out of their way to do so when these needs are heightened. For example, if someone loses his/her job or kids move away, the 
reduced sense of being needed and useful that may accompany such events could lead people to seek out ways to serve others' goals.

Of course, people do not always reap the potential benefits of serving as means to others. Our approach postulates that two conditions must be met in order for the person to experience the benefits of serving as a means (see also Inagaki \& Orehek, 2017; Orehek, in press; Orehek \& Weaverling, 2017). First, serving as a means should benefit the helper if s/he feels instrumental as a result. This can occur by observing progress or improvement in the goal pursuer's situation, such as when a child grows or develops, or when the goal pursuer expresses gratitude for one's help. Support efforts in which improvements are not made, such as when an ill person deteriorates or symptoms are merely maintained despite a person's devoted caretaking efforts should be frustrating, and should not lead to increased feelings of self-worth in the caretaker. People seem to adjust their behavior accordingly. For example, people are uninclined to provide support to partners who have a track record of consistent negativity — at least in part because they feel that their support efforts are unlikely to be instrumental in creating change (Forest, Kille, Wood, \& Holmes, 2014). Our approach postulates that experiences of burnout or fatigue are due to feelings of non-instrumentality rather than workload per se.

Second, the person serving as a means must feel that s/he has freely chosen to adopt the role of means, and therefore wants to serve as a means to the goal. Outcomes are likely to be suboptimal if one feels coerced or serves as a means to a goal that one does not wish to serve (Inagaki \& Orehek, 2017; Orehek, in press; Orehek \& Weaverling, 2017). Research has confirmed that people experience a boost in mood when helping others when that help is freely chosen, but not when it felt as if they did not have a choice (Weinstein \& Ryan, 2010). Similarly, unwanted praise or compliments can leave a person feeling uncomfortable or upset because the 
person delivering the positive message is placing the recipient in the position of serving as a means to goals they do not want to serve. When a person does not want to be a means to a particular goal, but is treated as a means to that goal anyway, that person is likely to feel objectified and to experience the negative consequences of objectification (Orehek \& Weaverling, 2017).

Thus, a people-as-means approach postulates that to keep one's relationship partners happy and fulfilled, one should give those partners the opportunity to be a means to one's goals. We suspect people realize that partners like us to serve as means to their goals (i.e., help them out, do nice things for them), but it is probably less obvious that we should also give our partners a chance to do things for us. This should enable them to feel useful, valuable, and efficacious. To the extent that people acknowledge the help they have received or express gratitude for it, the benefits for the instrumental partner and for the relationship may be heightened (e.g., Algoe, Gable, \& Maisel, 2010; Algoe, Haidt, \& Gable, 2008; Kubacka, Finkenauer, Rusbult, \& Keijsers, 2011), at least in part because such acknowledgement signals that the help was instrumental. In addition, just as people evaluate partners more positively when those partners serve many goals (Principle 4), our approach postulates that people experience greater feelings of selfworth and social connection when they, themselves, serve as a means to multiple goals for partners. Serving as a means to multiple goals should: (a) make people feel that their partners are more dependent on them, thus enhancing feelings of security (e.g., Murray, Aloni et al., 2009); (b) make people confident that even if they lose the ability to be instrumental in one domain or if their partner no longer pursues a particular kind of goal, they will still be able to offer their partner other things; (c) make it harder for partner to find an alternative partner who could do all of the things they do for the partner. 


\section{Implications for Interpersonal Relationships}

Our people-as-means account has important implications for understanding relationship dynamics. Below we examine some of these implications at different stages of relationships, including relationship initiation, maintenance, dissolution, and loss.

\section{Relationship Initiation and Evaluation}

The evidence we have reviewed supports the ideas that people perceived as high quality means to a goal are attended to, evaluated positively, and readily approached while the goal to which they are instrumental is being pursued (Principles 1 and 3). Whether evaluating a job candidate via her resume, a romantic prospect on a dating website, or one's best friend, people evaluate others according to their perceived instrumentality to current or future goals. Our people-as-means approach postulates that central relationship evaluations, such as liking, relationship satisfaction, relationship commitment, interpersonal closeness, perceived support, and perceived responsiveness should be derived from perceived instrumentality of the person being evaluated.

Our approach postulates that the number of goals a partner serves should also be associated with people's evaluations of that partner: Partners who are instrumental to multiple goals (i.e., are multifinal) should be evaluated more positively than people who serve fewer goals because they are able to facilitate more goal pursuit (Principle 4). Thus, we expect that people will find others who are instrumental to a greater number of goals (versus fewer goals) to be more supportive, responsive, and likeable, and to feel interpersonally closer to them. However, such multifinal partners should be more difficult to find than unifinal, or task-specific, partners. It may be easy to find another person with whom you enjoy playing tennis. There are far fewer people with whom you enjoy playing tennis, studying for exams, attending concerts, and going 
shopping for clothes. The scarcity of such multifinal partners may make them all the more desirable and appreciated.

From our people-as-means perspective, one reason why partner responsiveness is so important (Reis \& Shaver, 1988; Reis et al., 2004) is because it serves as a signal that a partner is likely to be willing and available to be a means to many goals that one might pursue. Responsive partners should be better at tracking goal shifts and needs across time, and also more motivated to meet those needs. Similarly, partners who are perceived as supportive are expected to be available to support future pursuits, whatever they may be (e.g., Lakey \& Orehek, 2011). Partners who are instrumental to a variety of goals are especially valuable because they are also the people who are likely to adapt in a way that they are instrumental to future unknown goals. Thus, responsiveness and the motivation to be supportive are characteristics of relationship partners that are likely to produce sustained instrumentality over time. Although having a particular skill or expertise in a goal domain can help someone be instrumental, such skill is not sufficient in the absence of motivation to help the other person. In addition, there are many ways in which a person can be instrumental to a goal. If my goal is running a marathon, having a partner who is an expert marathoner and can accompany me on training runs could be an asset, but a non-expert partner could do many other things to facilitate my pursuit of this goal (e.g., providing childcare so I have time to train, laundering my running clothes, helping me learn the course topography, or providing support and encouragement on race day). Responsive and supportive partners may have the will, or the motivation to help their partner (Winczewski, Bowen, \& Collins, 2016), and therefore will find a way to do so.

However, one intriguing possibility suggested by our approach is that the perceived instrumentality of a relationship partner to one goal may become diluted if that partner serves as 
a means to additional goals (Principle 5). If this happens, then it suggests that the global high evaluation of a multifinal partner comes at the expense of perceiving the partner as less instrumental to each particular goal that s/he serves. For example, consider a case in which a romantic partner is first merely perceived as an instrumental means to enjoyable nights out. Over time, that partner demonstrates that $\mathrm{s} / \mathrm{he}$ is instrumental for contributing to household tasks, for having enjoyable intellectual conversations, for helping with one's finances, and eventually for being a skilled and caring co-parent. Although the multifinality of this partner should increase one's felt closeness to him/her (along with perceived support, and other positive evaluations), the dilution principle suggests that one's perception of the partner as a fun date may decrease. Thus, there may be a tradeoff between perceptions of overall instrumentality (and associated relational outcomes) and instrumentality toward any particular goal. If this happens, then the person may stop looking to the partner to fulfill the diluted goal and/or may turn to alternative partners to fulfill that goal.

Yet, as reviewed earlier, each of the factors that mitigate the dilution effect tend to be present in cases in which people serve as means. Because the goals people serve tend to be compatible with one another, we do not expect dilution to be common among well-known others. In the example above, a partner who is a good co-parent can make date night more fun by having enjoyable conversations about their children. However, situations in which the partner is not well-known, such as when one learns about a partner on an online dating website, may be more likely to produce dilution because the compatibility of the various goals may be less obvious. Research has demonstrated that early impressions from online dating sites, speed dating, and other first encounters can differ markedly from impressions formed over time (e.g., Hunt, Eastwick, \& Finkel, 2015). An interesting possibility is that dilution may represent a form of 
evaluation error. If people in lasting relationships do not experience dilution, but people forming first impressions perceive dilution, then early impressions may be overly pessimistic with respect to a partner's ability to serve many goals. These possibilities have important implications for the utility of platforms that attempt to aid in match-making, such as online dating websites (Finkel, Eastwick, Karney, Reis, \& Sprecher, 2012).

Although instrumental others are appreciated for the support they provide, an important caveat is that such appreciation may be fleeting. Once the goal has been attained and the actor has moved on to other pursuits, appreciation for the instrumental partner tends to wane (Converse \& Fishbach, 2012; Fitzsimons \& Shah, 2008; Fitzsimons \& Fishbach, 2010; Fitzsimons, Friesen, Orehek, \& Kruglanski, 2009). One challenge for maintaining interpersonal closeness, then, is to transform these momentary experiences of appreciation into lasting sentiments. The present perspective offers two novel predictions regarding avenues by which people can do so. First, a partner can serve as a means to goals that are fundamental to the person pursuing them and to goals that are unlikely to be (fully) satiated by other partners. In other words, striving to serve goals that the goal pursuer is unlikely to ever cease pursuing may enable a person to remain instrumental and close to a partner over time. The need for social connection and belonging are goals that likely meet these criteria (e.g., Baumeister \& Leary, 1995). Second, a partner can strive to be instrumental to multiple goals, so that even if one of the goal pursuer's goals is satisfied, the partner remains instrumental to the next goal that is pursued. One's closest others are likely to be those who serve a variety of goals, making it easy to spend substantial amounts of time engaged in a variety of mutually rewarding tasks together. If a close other satisfies fundamental needs and serves a large set of goals, then appreciation for that person should be relatively constant. If, however, a person serves a smaller set of less grand goals (e.g., 
one's course instructor, who serves only a limited number of goals related to the academic domain), then appreciation for that person is likely to be limited both to times and contexts in which that person is instrumental.

Because goals change as a person moves through life, people likely seek partners who serve as means to their new goals and stop relying on people who served as means to previous goals but who are no longer useful. In order for a person to continue to be close to a partner, s/he must remain instrumental to the goals of the moment (for a similar argument related to attraction, see Finkel \& Eastwick, 2015). For example, parents' roles shift as their children develop, and the behaviors they enact to remain instrumental to their children should shift as a result. In romantic relationships, newlyweds may serve as instrumental means to having children, setting up a home, and for helping each other find suitable career paths. However, once the children seem to be doing well, the house is settled, and one's career is stable, these goals may no longer garner as much attention. Thus, one's partner who was instrumental to realizing their dream life may be viewed as dull because s/he does not seem to be serving goal striving. The well-known benefits for relationships of engaging in novel, exciting activities (Aron, Norman, Aron, McKenna, \& Heyman, 2000) may emerge, at least in part, because such activities provide an avenue for partners to serve as means to shared goals. Thus, it is important that one's partner is instrumental to the goals of the moment in order to maintain interpersonal closeness and relationship satisfaction.

When considered in light of a people-as-means account, it is not surprising that people often attempt to be a unique and irreplaceable means in order to remain important to a partner, and in their own eyes (Murray, Leder et al., 2009; Orehek \& Forest, 2016; Orehek \& Weaverling, 2017). To do this, they may serve as exclusive means to particular goals (e.g., by 
serving a goal no one else currently serves or by actively trying to prevent other people from serving as means to goals that one serves), or may be multifinal in a way that is unlikely to be reproduced by another person. In monogamous romantic relationships, partners serve as the exclusive means to sex. In friendships, one friend may relish being the only person in on a secret, or the only person who shares a particular interest. For goals to which the partner is the exclusive (possible or actual) means, being instrumental may afford greater relational benefit than would instrumentality to goals that are also served by other people. However, a lack of instrumentality in the former relationship types would pose a more serious challenge to the relationship.

Each of the foregoing ideas also applies to the person serving as the means. When one is instrumental to his or her partner's goals, then s/he feels interpersonally closer and derives a sense of self-worth (Inagaki \& Orehek, 2017). Our people-as-means approach makes the novel prediction that being instrumental to multiple goals for a particular partner should increase feelings of connection to that partner and should enhance self-worth as compared to serving fewer goals. This suggests that people may be better off looking for partners whom they can assist in many life domains rather than finding someone whom they can help with one focal goal. In addition, it highlights the fact that fitting a partner's multiple goals is just as important as having a partner fit one's own set of goals. The person serving as the means' willingness and ability to notice when a partner has new goals and become a means to them should contribute to relationship quality. People serving as means who want to be supportive and who are responsive to their partners should be better suited to shifting their efforts dynamically in a way that suits their partners' needs (cf. Fitzsimons et al., 2015; Lakey \& Orehek, 2011). Future research could explore how these features predict sustained instrumentality.

Considering partners as means to goals allows for a new understanding of the propinquity 
effect. Research has revealed the power of physical closeness in determining social ties (Festinger, Schachter, \& Back, 1950; Segal, 1974). One reason why close physical distance and frequent encounters may promote social connection is because each occasion in which a person is encountered presents the opportunity for that partner to be perceived as instrumental to one's goals (and for one to be instrumental to that person's goals). This can lead a person to adopt new goals to fit with the people who are present as well. Smart goal pursuit in an interpersonal context is not just about what is already most important to the actor, but also what is possible and what partners are available to help. Thus, people often observe the partners who are available, and then align action to fit with the context. If a person frequently encounters a particular partner, then it becomes more likely that the person eventually figures out ways the partner may be instrumental and begin a relationship with that person.

\section{Relationship Maintenance}

When a person is committed to a relationship partner (regardless of relationship type), maintaining the relationship becomes a goal in its own right. Although many of the processes reviewed in the previous section may occur passively when a person has a partner who serves as a means or when they themselves serve as a means, the person can also actively attempt to maintain a relationship once that relationship has become a goal. Just as a person who rides a bike as transportation to work must maintain and care for the bike (e.g., repairing it, securing it with a lock, etc.), a person who begins a relationship with someone who facilitates their goal pursuits must also maintain and care for the relationship with the person (Orehek, in press). However, even when maintaining a means (bike or relationship partner) becomes a goal, it continues to be evaluated according to its instrumentality as a means. The person still evaluates 
the bike according to its usefulness for transportation, and a relationship partner according to his/her instrumentality, even after a maintenance goal is formed.

Engaging in relationship maintenance behaviors is an important part of partner retention (Buss \& Shackelford, 1997; Buss, 1988). Our people-as-means offers unique insights into tactics available to retain a partner, which are applicable across relationship types. A person may protect his or her relationship with a current partner by engaging in the following tactics: (1) becoming a more instrumental means to one's partner, (2) allowing or providing opportunities for one's partner to become more instrumental to oneself, (3) preventing rivals from becoming instrumental means to one's partner, (4) preventing one's partner from becoming instrumental to rivals, (5) preventing oneself from becoming an instrumental means to alternative partners, or (6) preventing alternative partners from becoming an instrumental means to oneself. We review each of these in turn.

The first two tactics involve increasing interpersonal closeness with one's partner. This can be accomplished by enacting behaviors that increase felt closeness and commitment on the part of one's partner. A person can become more instrumental to his/her partner and/or can facilitate their partner's instrumentality to them. One way to do this is to increase the number of goals each person serves for the other person. Other possibilities include increasing the frequency or competence with which one person serves the other's goals, ensuring that partners are serving each other's most important goals of the moment, and ensuring that each person recognizes and appreciates all of the ways the other person is instrumental.

Tactics 3 and 4 involve keeping rivals away from one's partner, referred to as mate guarding in romantic relationships. These tactics can be employed in other relationships as well, such as when siblings compete for a parent's affection, when employees vie for recognition from 
a supervisor, or when several close friends angle for the honor of serving as bridesmaid. Rivals can be pushed away from one's partner by blocking access to the partner or by engaging in competition with rivals (Arnocky et al., 2014). Blocking access to the partner on the part of the rival prevents the rival from becoming instrumental to the partner and prevents the partner from becoming instrumental to the rival (a role that could increase felt closeness). Competing with rivals is an attempt to be more instrumental than the rival, or at least to convince the partner that one is more instrumental than the rival. This could be accomplished by actually outperforming the rival in terms of instrumentality, or trying to alter the partner's subjective perceptions of relative instrumentality by glamorizing one's own abilities or contributions and/or disparaging the rival on these dimensions (Buss \& Dedden, 1990; Schmitt \& Buss, 1996).

Tactics 5 and 6 involve keeping oneself away from alternative partners, a process that we have termed relationship shielding. This can be accomplished by preventing oneself from being a means to others and/or by preventing others from being instrumental to oneself. For example, a person can limit his/her appeal or attractiveness to potential partners (Forest, Krueger, \& Orehek, 2017; Frankenhuis \& Karremans, 2012) and can avoid opportunities to help others progress toward their goals. Preventing alternatives from seeming instrumental can be executed by devaluing alternative partners (Karremans et al., 2011; Lydon et al., 2003; Lydon et al., 1999) and by directing attention away from alternatives (Linardatos \& Lydon, 2011; Maner et al., 2009).

Whereas previous research involving romantic relationships has focused on devaluing the physical attractiveness of alternatives, the present perspective postulates that these effects should occur across goal domains. For example, a partner may want to avoid emotional infidelity, which results from mutual perceived instrumentality with someone that exceeds an appropriateness 
threshold. People can protect romantic relationships by having others (aside from the focal relationship partner) serve as means to goals that do not threaten the relationship (i.e., safe goals). For example, having a friend serve as a means to playing tennis might be a safer goal than having that friend serve as a means to back massages. Another way to protect romantic relationships would be to have close others who are non-threatening to the relationship, such as close kin or friends of a different gender than one's romantic partner (i.e., safe targets), serve as means to important goals. Finally, members of one's social network can serve as means to retaining one's romantic partner by making it more likely that the relationship will last (termed coalitional mate retention, Barbaro, Pham, \& Shackelford, 2015; Barbaro, Shackelford, \& Weekes-Shackelford, 2016; Pham, Barbaro, \& Shackelford, 2015; Pham, Barbaro, Mogliski, \& Shackelford, 2015). For example, friends may praise a person to his or her partner, may help keep rivals away from the partner, or may provide information about a gift the partner would cherish. Moreover, our perspective postulates that shielding tactics should also be enacted in non-romantic relationships.

\section{Partner Substitution}

Our perspective uniquely postulates that partner substitution-replacing one partner with another-occurs for one of two reasons. First, partner substitution can occur when available alternatives are perceived to be more instrumental than one's current partner. An alternative should be perceived as more instrumental when s/he serves more goals or when s/he is more instrumental to one's current goals than one's current partner is. Such a relative valuation of an alternative over one's partner can occur simply because a highly instrumental alternative has become available, or because one's partner has decreased in perceived instrumentality over time. 
A decrease in perceived instrumentality can occur because the partner has ceased to be instrumental to goals s/he used to serve, or because one's goals have changed.

Second, partner substitution can occur when an available alternative affords the person greater opportunity to be instrumental themselves. This could occur when the person perceives him-or-herself as more instrumental in helping the alternative partner (compared to the current partner) to reach his or her goals. Because serving as an instrumental means increases feelings of self-worth and social connection (e.g., Inagaki \& Orehek, 2017), an alternative partner who makes this possible is desirable. An alternative partner can appear desirable because s/he allows the person to serve more goals than the current partner or because s/he allows the person to serve different goals than the current partner.

Within monogamous romantic relationships, emotional or sexual infidelity — in which a person engages in a relationship with an alternative partner but does not want to leave the longterm relationship—should occur for different reasons than permanent partner substitution. Infidelity is likely to occur because the person perceives the alternative partner to be instrumental for some goal(s) the long-term partner is not fulfilling or because the alternative affords the opportunity for the person to serve as a means to one of the alternative's goals that the person is not able to serve for the long-term partner. Alternative partners should often be less instrumental and/or allow oneself to be less instrumental overall compared to one's long-term partner, and may be quite different from one's long-term partner precisely because they serve different goals. A person's long-term partner may be very instrumental overall and may satisfy many of the person's most important goals, such as having children, invested parenting, social connection, high status, and financial security. However, because one's current partner has satisfied many important goals, momentary considerations and particular contexts may increase the 
attractiveness of alternative partners who serve unfulfilled goals — even if those goals are not as important as the ones served by the long-term partner. Similarly, a person's long-term partner may afford the person the opportunity to be instrumental to many of the partner's goals. However, because the person has satisfied many of their partner's goals, momentary considerations and particular contexts may increase the attractiveness of alternative partners who allow one to serve new or shared goals - even if those goals are not as important as the ones served for the long-term partner.

Such a process may partially explain why people sometimes commit infidelity with partners whom they perceive to be of lower value than their long-term partner. If the person had higher overall value, then the person should be more likely to permanently leave a current partner in favor of the alternative. Each of the notions above suggests that changing contexts, such as starting a new career or moving to a new city, should increase the likelihood of relationship dissolution (Fitzsimons et al., 2015). As person's goals change, a partner may no longer appear to be the best candidate. As a person encounters new people and discovers new ways to be instrumental to others, s/he may wish to take on those new roles.

\section{Relationship Loss}

People can lose a partner either because one person decides to end the relationship, the partners become more distant over time, or the partner dies. From our perspective, when a person loses a partner, s/he loses a means to goals. S/he also loses a partner to whom s/he served as a means. The previous partner who served as a means is no longer available to serve as a reminder to pursue certain goals (Principle 2). The more goals the partner served, the more the person should feel the loss (Principle 4). In addition, the more goals a person served for their partner, the more the loss should be felt. The loss of one partner should relax attempts at shielding alternative 
partners (Principle 7). Because of this, alternative partners may intuitively step up in an attempt to fill the role of the lost partner. Losing a means to one's goals can be disruptive to one's goal pursuit. Among widowed individuals, those who were highly dependent on their spouse experience more anxiety than those who were less dependent (Carr et al., 2000). It is possible that some of this anxiety may be the result of lost instrumentality. Indeed, when people go through a break-up with a partner who was instrumental to their goals, those people experience disruptions in goal progress (Gomillion, Murray, \& Lamarche, 2015). As a result, people must decide whether to locate new means to those goals, to lean more heavily on existing means, or to abandon pursuit of the goal altogether, perhaps replacing it with a new goal to which means are available. When people derive gratification and a sense of self-worth from serving a partner's goals, they should suffer losses on these dimensions when they lose the partner.

When someone loses a relationship partner, either through relationship termination, gradual distancing, or death, other partners can be helpful by serving as a means to goals previously filled by the lost partner, and allowing the person who has suffered the loss to serve as a means to their goals - either goals the person previously filled for the lost partner, or new goals. Romantic break-ups have been shown to lead to reductions in self-concept clarity, which predict post-dissolution distress (Slotter, Gardner, \& Finkel, 2010). When a person can regain means to his/her important goals and feel that he/she is instrumental to other people's goals, we expect that this should help to restore self-concept clarity, minimize the disruption posed by the loss, and facilitate coping.

\section{Connections and Contrasts with Existing Relationship Theories}

Relationship researchers have long acknowledged the important role that role that close relationship partners play in one another's goal pursuits. For example, attachment theory posits 
that partners serve as a secure base from which to engage in exploration (Bowlby, 1988; Feeney, 2004; Hazan \& Shaver, 1990). Interdependence theory (Kelley \& Thibaut, 1978) recognizes that partners can provide one another with rewards and costs, and are dependent on one another to the extent that they influence one another's outcomes. The present perspective builds on previous theories by detailing the principles that govern how people serve as means and the specific implications for relationship initiation, maintenance, and dissolution. In addition, our perspective enables us to make predictions about relationship processes and outcomes in a variety of relationship types, including close relationships (e.g., romantic relationships, family relationships, and friendships) and relationships with more distant partners (e.g, acquaintances, colleagues, service providers and recipients).

A people-as-means perspective offers new insights into classic theoretical perspectives and principles in the area of close relationships. We consider some relevant examples here. According to the investment model (an extension of interdependence theory; Rusbult, 1980; 1983; Rusbult et al., 2012), people's commitment to their relationships is a function of three factors: their relationship satisfaction, the investments they have made in the relationship, and the quality of their alternatives to the relationship. From our perspective, relationship satisfaction should be felt when a partner is instrumental; investments reflect dependence on a partner for continued instrumentality; and alternatives should be evaluated according to their instrumentality. In addition, we have suggested that one should experience relationship satisfaction when a partner allows one to be instrumental to that partner investments reflect dependence on the partner for continuing to allow oneself to be instrumental, and alternative partners should be evaluated according to how much they afford opportunities for one to be an instrumental agent. While the investment model was especially novel because it could explain 
why people stay in harmful (e.g., abusive) or unsatisfying relationships (e.g., due to investments, and/or poor alternatives; Rusbult \& Martz, 1995), our model is novel because it explains why some people may relish relationships in which they have especially needy partners, and how they can benefit from caretaking.

The Michelangelo Phenomenon concerns how relationship partners help one another strive for and achieve their goals through affirmation (Drigotas, Rusbult, Wieselquist, \& Whitton, 1999; Rusbult, Finkel, \& Kumashiro, 2009). We suggest that affirming a partner's goal strivings is one way in which people serve as means, and people should benefit (via increased sense of self-worth and felt connection with the partner) when they affirm a partner's strivings. Of course, people can also be instrumental to partner's goal pursuit in many other ways. Theorists have made a distinction between communal and exchange relationships, emphasizing that benefits are given freely in response to needs in communal relationships and that reciprocity is expected in exchange relationships (Clark \& Mills, 1979; Mills \& Clark, 1982; Clark \& Mills, 2011). This perspective assumes that the person giving a benefit to another person incurs some cost (and will only provide the benefit up to some "cost threshold"). We do not make this assumption, and instead emphasize the benefits of helping others (see also Williamson \& Clark, 1989). A communal/exchange perspective would predict that people want to be instrumental to a partner if they care about the partner's welfare (i.e., when a communal relationship exists or is desired). Communal/exchange theorists have nicely demonstrated that caring for others is a cause of instrumental behavior. To this, we add the proposition that people's care for others can also be a result of instrumentality.

Most recently, Transactive Goal Dynamics Theory (TGD; Fitzsimons, Finkel, \& VanDellen, 2015) presented an innovative approach to understanding how relationship partners 
form a single self-regulating system. TGD is focused on understanding the antecedents and consequences of partners exhibiting transactive density - a new TGD construct defined as "the extent to which dyads have numerous and strong links among member's goals, pursuits, and outcomes" (Fitzsimons et al., 2015, pp. 650). Our approach shares with TGD a general emphasis on the interpersonal nature of goal pursuit. However, our approach focuses on how specific principles of goal pursuit drawn from Goal Systems Theory (Kruglanski et al., 2002) influence relationship processes. Our approach and TGD are complementary perspectives. From our perspective, the most important prediction TGD makes about relationships is that people are more likely to remain in relationships in which partners experience better goal outcomes while working together toward goals than they would alone - an effect partially due to perceived instrumentality of the partner. We importantly add specific goal systemic principles that detail when partners will be perceived as instrumental (including an emphasis on multifinality). Our approach also adds the observation that people evaluate relationships based on the opportunity they afford for oneself to be instrumental to a partner. In addition, we expect that people will make comparisons between one's partner as a means and alternative partners who could serve as means (as compared to the TGD comparison to pursuing the goal alone).

Another difference between our approach and TGD that is worth noting is that we emphasize that a partner who serves as a means to a particular goal will be replaced by an alternative partner who serves as a more instrumental means to that goal. Thus, rather than predicting relationship duration based on the sum of one's contributions to goal pursuit overall as compared to goal pursuit alone (the comparison emphasized in TGD), we predict continuation of a person serving a role as a means to a specific goal based on their instrumentality to that goal as compared to alternative partners. Once a partner is no longer serving as a means to any goals, 
then the relationship with that partner should be discontinued. Therefore, we expect relationships to continue when a partner continues to be instrumental (and allow oneself to be instrumental) and to end when a partner ceases to be instrumental (and the person is no longer instrumental to the partner).

\section{Conclusions}

Our people-as-means framework suggests that people form and maintain relationships with partners who are instrumental to important goals, and dissolve relationships when a partner is no longer instrumental or when a more instrumental alternative is available. In addition, people often like to serve as means to goals. They derive a sense of personal importance, esteem, and value from their ability to help others. They also feel closer and more connected to the people they help. A consideration of both people in the dyad—who are each goal pursuers and meansleads to our principle of mutual perceived instrumentality. We suggest that when both people in a relationship feel that they and their partner are instrumental to one another, relationships are more likely to endure and to thrive. 


\section{References}

Aarts, H., \& Dijksterhuis, A. (2000b). The automatic activation of goal-directed behaviour: The case of travel habit. Journal of Environmental Psychology, 20, 75-82.

Aarts, H., Gollwitzer, P. M., \& Hassin, R. R. (2004). Goal contagion: perceiving is for pursuing. Journal of Personality and Social Psychology, 87, 23-37.

Algoe, S. B., Gable, S. L., \& Maisel, N. C. (2010). It's the little things: Everyday gratitude as a booster shot for romantic relationships. Personal relationships, 17(2), 217-233.

Algoe, S. B., Haidt, J., \& Gable, S. L. (2008). Beyond reciprocity: gratitude and relationships in everyday life. Emotion, 8(3), 425-429.

Arnocky, S., Ribout, A., Mirza, R. S., \& Knack, J. M. (2014). Perceived mate availability influences intrasexual competition, jealousy and mate-guarding behavior. Journal of Evolutionary Psychology, 12, 45-64.

Aron, A., Norman, C. C., Aron, E. N., McKenna, C., \& Heyman, R. E. (2000). Couples' shared participation in novel and arousing activities and experienced relationship quality. Journal of Personality and Social Psychology, 78, 273-284.

Baker Jr., M. D., \& Maner, J. K. (2009). Male risk-taking as a context-sensitive signaling device. Journal of Experimental Social Psychology, 45, 1136-1139.

Barbaro, N., Pham, M. N., \& Shackelford, T. K. (2015). Solving the problem of partner infidelity: Individual mate retention, coalitional mate retention and in-pair copulation frequency. Personality and Individual Differences, 82, 67-71.

Barbaro, N., Shackelford, T. K., \& Weekes-Shackelford, V. (2016). Mothers and fathers perform more mate retention behaviors than individuals without children. Human Nature, 27, 316333. 
Baumeister, R. F., \& Leary, M. R. (1995). The need to belong: Desire for interpersonal attachments as a fundamental human motivation. Psychological Bulletin, 117, 497-529.

Bowlby, J. (1988). A secure base. New York: Basic Books.

Buss, D. M. (1988). From vigilance to violence: Tactics of mate retention in American undergraduates. Ethology and Sociobiology, 9, 291-317.

Buss, D.M. \& Dedden, L.A. (1990). Derogation of competitors. Journal of Social \& Personal Relationships, 7, 395-422.

Buss, D. M., Goetz, C., Duntley, J. D., Asao, K., \& Conroy-Beam, D. (2017). The mate switching hypothesis. Personality and Individual Differences, 104, 143-149.

Buss, D. M., \& Shackelford, T. K. (1997). From vigilance to violence: mate retention tactics in married couples. Journal of Personality and Social Psychology, 72, 346-361.

Carr, D., House, J. S., Kessler, R. C., Nesse, R. M., Sonnega, J., \& Wortman, C. (2000). Marital quality and psychological adjustment to widowhood among older adults: A longitudinal analysis. The Journals of Gerontology Series B: Psychological Sciences and Social Sciences, 55(4), S197-S207.

Chun, W. Y., Kruglanski, A. W., Sleeth-Keppler, D., \& Friedman, R. S. (2011). Multifinality in implicit choice. Journal of Personality and Social Psychology, 101, 1124-1137.

Clark, M.S. (1984). Record keeping in two types of relationships. Journal of Personality and Social Psychology, 47, 549-557.

Clark, M.S. \& Aragon, O. (2014). Communal (and other) relationships: History, theory development and future directions. In J. Simpson \& L. Campbell (Eds.) Handbook of Close Relationships. Oxford, England: Oxford University Press. 
Clark, M. S., \& Mills, J. (1979). Interpersonal attraction in exchange and communal relationships. Journal of Personality and Social Psychology, 37, 12-24.

Clark M.S., Mills, J. (2011). A theory of communal (and exchange) relationships. In Van Lange P.A.M., Kruglanski A.W., Higgins E.T. (Eds.), Handbook of theories of social psychology (pp. 232-250). Thousand Oaks, CA: Sage.

Clark, M.S., Mills, J., \& Corcoran, D. (1989). Keeping track of needs and inputs of friends and strangers. Personality and Social Psychology Bulletin, 15, 533-542.

Clark, M.S., Mills, J., \& Powell, M. (1986). Keeping track of needs in two types of relationships. Journal of Personality and Social Psychology, 51, 333-338.

Cole, S., Trope, Y., \& Balcetis, E. (2016). In the Eye of the Betrothed: Perceptual Downgrading of Attractive Alternative Romantic Partners. Personality and Social Psychology Bulletin, 42(7), 879-892.

Conroy-Beam, D., Goetz, C. D., \& Buss, D. M. (2016). What predicts romantic relationship satisfaction and mate retention intensity: mate preference fulfillment or mate value discrepancies?. Evolution and Human Behavior, 37, 440-448.

Converse, B. A., \& Fishbach, A. (2012). Instrumentality boosts appreciation: Helpers are more appreciated while they are useful. Psychological Science, 23, 560-566.

Cox, C. R., Arndt, J., Pyszczynski, T., Greenberg, J., Abdollahi, A., \& Solomon, S. (2008). Terror management and adults' attachment to their parents: the safe haven remains. Journal of Personality and Social Psychology, 94, 696-717.

Custers, R., Eitam, B., \& Bargh, J. A. (2012). Conscious and unconscious processes in goal pursuit. In H. Aarts \& A. J. Elliot (Eds), Goal-Directed Behavior (pp. 231-266). New York: Psychology Press. 
Danner, U. N., Aarts, H., \& de Vries, N. K. (2007). Habit formation and multiple means to goal attainment: Repeated retrieval of target means causes inhibited access to competitors. Personality and Social Psychology Bulletin, 33, 1367-1379.

Drigotas, S. M., Rusbult, C. E., Wieselquist, J., \& Whitton, S. W. (1999). Close partner as sculptor of the ideal self: behavioral affirmation and the Michelangelo phenomenon. Journal of Personality and Social Psychology, 77, 293-323.

Eastwick, P. W., Finkel, E. J., \& Eagly, A. H. (2011). When and why do ideal partner preferences affect the process of initiating and maintaining romantic relationships?. Journal of Personality and Social Psychology, 101, 1012-1032.

Eastwick, P. W., \& Hunt, L. L. (2014). Relational mate value: Consensus and uniqueness in romantic evaluations. Journal of Personality and Social Psychology, 106(5), 728-751.

Feeney, B. C. (2004). A secure base: Responsive support of goal strivings and exploration in adult intimate relationships. Journal of Personality and Social Psychology, 87, 631-648.

Festinger, L., Back, K. W., \& Schachter, S. (1950). Social pressures in informal groups: A study of human factors in housing (Vol. 3). Stanford University Press.

Finkel, E. J., \& Eastwick, P. E. (2015). Interpersonal attraction: In search of a theoretical Rosetta stone. Handbook of personality and social psychology: Interpersonal relations and group processes. Washington, DC: American Psychological Association.

Finkel, E. J., Hui, C. M., Carswell, K. L., \& Larson, G. M. (2014). The suffocation of marriage: Climbing Mount Maslow without enough oxygen. Psychological Inquiry, 25, 1-41.

Fishbach, A., Shah, J. Y., \& Kruglanski, A. W. (2004). Emotional transfer in goal systems. Journal of Experimental Social Psychology, 40, 723-738. 
Fitzsimons, G. M., \& Bargh, J. A. (2003). Thinking of you: nonconscious pursuit of interpersonal goals associated with relationship partners. Journal of Personality and Social Psychology, 84, 148-164.

Fitzsimons, G. M., Finkel, E. J., \& Vandellen, M. R. (2015). Transactive goal dynamics. Psychological Review, 122, 648-673.

Fitzsimons, G. M., \& Fishbach, A. (2010). Shifting closeness: interpersonal effects of personal goal progress. Journal of Personality and Social Psychology, 98, 535-549.

Fitzsimons, G. M., Friesen, J., Orehek, E., \& Kruglanski, A. (2009). Progress-induced goal shifting as a self-regulatory strategy. Psychology of self-regulation: Cognitive, affective, and motivational processes, 181-194.

Fitzsimons, G. M., \& Shah, J. (2008). How goal instrumentality shapes relationship evaluations. Journal of Personality and Social Psychology, 95, 319-337.

Forest, A. L., Kille, D. R., Wood, J. V., \& Holmes, J. G. (2014). Discount and disengage: How chronic negative expressivity undermines partner responsiveness to negative disclosures. Journal of Personality and Social Psychology, 107, 1013-1032.

Forest, A. L., Krueger, K., \& Orehek, E. (2017). Relationship commitment and attractivenessregulation with romantic alternatives. Unpublished data.

Frankenhuis, W. E., \& Karremans, J. C. (2012). Uncommitted men match their risk taking to female preferences, while committed men do the opposite. Journal of Experimental Social Psychology, 48, 428-431.

Gomillion, S., \& Murray, S. L. (2014). Shifting dependence: The influence of partner instrumentality and self-esteem on responses to interpersonal risk. Personality and Social Psychology Bulletin, 40, 57-69. 
Gomillion, S., Murray, S. L., \& Lamarche, V. M. (2015). Losing the wind beneath your wings: The prospective influence of romantic breakup on goal progress. Social Psychological and Personality Science, 6, 513-520.

Gruenewald, T. L., Liao, D. H., \& Seeman, T. E. (2012). Contributing to others, contributing to oneself: Perceptions of generativity and health in later life. The Journals of Gerontology Series B: Psychological Sciences and Social Sciences, 67, 660-665.

Hatfield, E., \& Rapson, R. L. (2011). Equity theory in close relationships. In P. A. M. Van Lange, A. W. Kruglanski, E. T. Higgins (Eds.) Handbook of Theories of Social Psychology Vol. 2 (pp. 200-217). Thousand Oaks, CA: Sage Publications.

Hatfield, E., Walster, G.W., \& Berscheid, E. (1978) Equity: Theory and Research. Boston: Allyn \& Bacon.

Hazan, C., \& Shaver, P. R. (1990). Love and work: An attachment-theoretical perspective. Journal of Personality and Social Psychology, 59, 270-280.

Horan, S. M., \& Booth-Butterfield, M. (2010). Investing in affection: An investigation of affection exchange theory and relational qualities. Communication Quarterly, 58, 394413.

Hunt, L. L., Eastwick, P. W., \& Finkel, E. J. (2015). Leveling the playing field: Longer acquaintance predicts reduced assortative mating on attractiveness. Psychological Science, 26(7), 1046-1053.

Inagaki, T. K., \& Eisenberger, N. I. (2012). Neural correlates of giving support to a loved one. Psychosomatic Medicine, 74, 3-7. 
Inagaki, T. \& Orehek, E. (2017). On the benefits of giving social support: When, why, and how support providers gain by caring for others. Current Directions in Psychological Science, 26, $109-113$.

Jecker, J., \& Landy, D. (1969). Liking a person as a function of doing him a favour. Human Relations. 4. 371-378.

Johnson, D. J., \& Rusbult, C. E. (1989). Resisting temptation: Devaluation of alternative partners as a means of maintaining commitment in close relationships. Journal of Personality and Social Psychology, 57, 967-980.

Karremans, J. C., Dotsch, R., \& Corneille, O. (2011). Romantic relationship status biases memory of faces of attractive opposite-sex others: Evidence from a reverse-correlation paradigm. Cognition, 121, 422-426.

Kavanagh, P. S., Fletcher, G. J. O., \& Ellis, B. J. (2014). The mating sociometer and attractive others: A double-edged sword in romantic relationships. The Journal of Social Psychology, 154, 126-141.

Kelley, H. H., \& Thibaut, J. W. (1978). Interpersonal relations: A theory of interdependence. John Wiley \& Sons.

Kenrick, D. T., Neuberg, S. L., Zierk, K. L., \& Krones, J. M. (1994). Evolution and social cognition: Contrast effects as a function of sex, dominance, and physical attractiveness. Personality and Social Psychology Bulletin, 20, 210-217.

Kjaer, T., Albieri, V., Jensen, A., Kjaer, S. K., Johansen, C., \& Dalton, S. O. (2014). Divorce or end of cohabitation among Danish women evaluated for fertility problems. Acta Obstetricia et Gynecologica Scandinavica, 93, 269-276. 
Köpetz, C., Faber, T., Fishbach, A., \& Kruglanski, A. W. (2011). The multifinality constraints effect: How goal multiplicity narrows the means set to a focal end. Journal of Personality and Social Psychology, 100, 810-826.

Kruglanski, A. W., Köpetz, C., Bélanger, J. J., Chun, W. Y., Orehek, E., \& Fishbach, A. (2013). Features of multifinality. Personality and Social Psychology Review, 17, 22-39.

Kruglanski, A. W., Pierro, A., \& Sheveland, A. (2011). How many roads lead to Rome? Equifinality set-size and commitment to goals and means. European Journal of Social Psychology, 41, 344-352.

Kruglanski, A. W., Shah, J., Fishbach, A., Friedman, R., Chun, W., \& Sleeth-Keppler, D. (2002). A theory of goal systems. Advances in Experimental Social Psychology (Vol. 34, pp. 331-378). San Diego, CA: Academic Press.

Kubacka, K. E., Finkenauer, C., Rusbult, C. E., \& Keijsers, L. (2011). Maintaining close relationships: Gratitude as a motivator and a detector of maintenance behavior. Personality and Social Psychology Bulletin, 37, 1362-1375.

Lakey, B. \& Orehek, E. (2011). Relational regulation theory: A new approach to explain perceived social support's link to mental health. Psychological Review, 118, 482-495.

Leander, N. P., Shah, J. Y., \& Chartrand, T. L. (2009). Moments of weakness: The implicit context-dependencies of temptations. Personality and Social Psychology Bulletin, 25, 853-866.

Leiblum, S. R., Aviv, A., \& Hamer, R. (1998). Life after infertility treatment: a long-term investigation of marital and sexual function. Human Reproduction, 13, 3569-3574.

Lewin, K. (1935). A dynamic theory of personality. New York, NY: McGraw-Hill.

Light, A. E., \& Fitzsimons, G. M. (2014). Contextualizing marriage as a means and a goal. 
Psychological Inquiry, 25, 88-94.

Linardatos, L., \& Lydon, J. E. (2011). Relationship-specific identification and spontaneous relationship maintenance processes. Journal of Personality and Social Psychology, 101, 737-753.

Lockwood, P., \& Kunda, Z. (1997). Superstars and me: Predicting the impact of role models on the self. Journal of Personality and Social Psychology,73, 91-103.

Lydon, J. E., Fitzsimons, G. M., \& Naidoo, L. (2003). Devaluation versus enhancement of attractive alternatives: A critical test using the calibration paradigm. Personality and Social Psychology Bulletin, 29, 349-359.

Lydon, J. E., Meana, M., Sepinwall, D., Richards, N., \& Mayman, S. (1999). The commitment calibration hypothesis: When do people devalue attractive alternatives? Personality and Social Psychology Bulletin, 25, 152-161.

Maner, J. K., Gailliot, M. T., \& Miller, S. L. (2009). The implicit cognition of relationship maintenance: Inattention to attractive alternatives. Journal of Experimental Social Psychology, 45, 174-179.

Maner, J. K., Gailliot, M. T., Rouby, D. A., \& Miller, S. L. (2007). Can't take my eyes off you: Attentional adhesion to mates and rivals. Journal of Personality and Social Psychology, 93, 389-401.

Meyer, M. L., Berkman, E. T., Karremans, J. C., \& Lieberman, M. D. (2011). Incidental regulation of attraction: The neural basis of the derogation of attractive alternatives in romantic relationships. Cognition and Emotion, 25, 490-505.

Mikulincer, M., Gillath, O., \& Shaver, P. R. (2002). Activation of the attachment system in adulthood: threat-related primes increase the accessibility of mental representations of 
attachment figures. Journal of Personality and Social Psychology, 83, 881-895.

Miller, R. S. (1997). Inattentive and contented: Relationship commitment and attention to alternatives. Journal of Personality and Social Psychology, 73, 758-766.

Miller, S. L., \& Maner, J. K. (2010). Evolution and relationship maintenance: Fertility cues lead committed men to devalue relationship alternatives. Journal of Experimental Social Psychology, 46, 1081-1084.

Millheiser, L. S., Helmer, A. E., Quintero, R. B., Westphal, L. M., Milki, A. A., \& Lathi, R. B. (2010). Is infertility a risk factor for female sexual dysfunction? A case-control study. Fertility and Sterility, 94, 2022-2025.

Mills, J., \& Clark, M. S. (1982). Exchange and communal relationships. Review of Personality and social Psychology, 3, 121-144.

Murray, S. L., Aloni, M., Holmes, J. G., Derrick, J. L., Stinson, D. A., \& Leder, S. (2009). Fostering partner dependence as trust insurance: The implicit contingencies of the exchange script in close relationships. Journal of Personality and Social Psychology, 96, 324-348.

Murray, S. L., Leder, S., MacGregor, J. C., Holmes, J. G., Pinkus, R. T., \& Harris, B. (2009). Becoming irreplaceable: How comparisons to the partner's alternatives differentially affect low and high self-esteem people. Journal of Experimental Social Psychology, 45, 1180-1191.

Myers, J. L., O'Brien, E. J., Balota, D. A., \& Toyofuku, M. L. (1984). Memory search without interference: The role of integration. Cognitive Psychology, 16, 217-242. 
Orehek, E. (in press). Goal Pursuit and close relationships: A people as means perspective. In C. Kopetz \& A. Fishbach (Eds.) The Motivation-Cognition Interface: From the Lab to the Real World.

Orehek, E., \& Forest, A. L. (2016). When people serve as means to goals: Implications of a motivational account of close relationships. Current Directions in Psychological Science, $25,79-84$.

Orehek, E., Forest, A. L., \& Wingrove, S. (2017). When people serve as means to multiple goals: Implications for perceived support, perceived responsiveness, and interpersonal closeness. Unpublished data.

Orehek, E., Mauro, R., Kruglanski, A. W., \& van der Bles, A. M. (2012). Prioritizing association strength versus value: the influence of self-regulatory modes on means evaluation in single goal and multigoal contexts. Journal of Personality and Social Psychology, 102, $22-31$.

Orehek, E. \& Vazeou-Nieuwenhuis, A. (2016). On the obesity problem: Policy implications of a motivational account of (un)healthy eating. Social Issues and Policy Review, 10, 151180.

Orehek, E., Vazeou-Nieuwenhuis, A., Quick, E., \& Weaverling, G. C. (2017). Attachment and self-regulation. Personality and Social Psychology Bulletin, 43, 365-380.

Orehek, E. \& Weaverling, C. G. (2017). On the nature of objectification: Implications of considering people as means to goals. Perspectives on Psychological Science.

Park, B. (1989). Trait attributes as on-line organizers in person impressions. On-line cognition in person perception, 39-59.

Pham, M. N., Barbaro, N., \& Shackelford, T. K. (2015). Development and initial validation of 
the coalitional mate retention inventory. Evolutionary Psychological Science, 1, 4-12.

Pham, M. N., Barbaro, N., Mogliski, J. K., \& Shackelfrod, T. K. (2015). Coalitional mate retention is correlated positively with friendship quality involving women, but negatively with male-male friendship quality. Personality and Individual Differences, 79, 87-90.

Piferi, R. L., \& Lawler, K. A. (2006). Social support and ambulatory blood pressure: an examination of both receiving and giving. International Journal of Psychophysiology, 62, $328-336$.

Reis, H. T., Clark, M. S., \& Holmes, J. G. (2004). Perceived partner responsiveness as an organizing construct in the study of intimacy and closeness. Handbook of closeness and intimacy, 201-225.

Reis, H. T., \& Shaver, P. (1988). Intimacy as an interpersonal process. Handbook of personal relationships, 24(3), 367-389.

Rusbult, C. E. (1980). Commitment and satisfaction in romantic associations: A test of the investment model. Journal of Experimental Social Psychology, 16, 172-186.

Rusbult, C. E. (1983). A longitudinal test of the investment model: The development (and deterioration) of satisfaction and commitment in heterosexual involvements. Journal of Personality and Social Psychology, 45, 101-117.

Rusbult, C. E., Agnew, C., \& Arriaga, X. (2012). The investment model of commitment processes. In P. Van Lange, A. Kruglanski, \& E. Higgins (Eds.), Handbook of theories of social psychology (pp. 218-232). London, England: Sage.

Rusbult, C. E., Finkel, E. J., \& Kumashiro, M. (2009). The Michelangelo phenomenon. Current Directions in Psychological Science, 18, 305-309.

Rusbult, C. E., \& Martz, J. M. (1995). Remaining in an abusive relationship: An investment 
analysis of nonvoluntary dependence. Personality and Social Psychology Bulletin, 21, 558-571.

Schmitt, D.P. \& Buss, D.M. (1996). Strategic self-promotion and competition derogation: Sex and conflict effects on perceived effectiveness of mate attraction tactics. Journal of Personality and Social Psychology, 70, 1185-1204.

Schmitt, D. P., \& Buss, D. M. (2001). Human mate poaching: Tactics and temptations for infiltrating existing relationships. Journal of Personality and Social Psychology, 86, 560584.

Segal, M. W. (1974). Alphabet and attraction: An unobtrusive measure of the effect of propinquity in a field setting. Journal of Personality and Social Psychology, 30, 654-657.

Shah, J. (2003). Automatic for the people: How representations of significant others implicitly affect goal pursuit. Journal of Personality and Social Psychology, 84, 661-681.

Shah, J. Y. (2005). The automatic pursuit and management of goals. Current Directions in Psychological Science, 14, 10-13.

Shah, J. Y., Hall, D., \& Leander, N. P. (2009). Moment of motivation: Margins of opportunity in managing the efficacy, need, and transitions of striving. In G. B. Moskowitz, \& H. Grant (Eds.), The psychology of goals (234-254). New York: Guilford Press.

Shah, J. Y., Friedman, R., \& Kruglanski, A. W. (2002). Forgetting all else: On the antecedents and consequences of goal shielding. Journal of Personality and Social Psychology, 83, 1261-1280.

Shah, J. Y., \& Kruglanski, A. W. (2002). Priming against your will: How accessible alternative affect goal pursuit. Journal of Experimental Social Psychology, 38, 368-383.

Shah, J. Y., \& Kruglanski, A. W. (2003). When opportunity knocks: Bottom-up priming of goals 
by means and its effects on self-regulation. Journal of Personality and Social Psychology, 84, 1109-1122.

Sheeran, P., Aarts, H., Custers, R., Rivis, A., Webb, T. L., \& Cooke, R. (2005). The goaldependent automaticity of drinking habits. British Journal of Social Psychology, 44, 4763.

Simpson, J. A., Gangestad, S. W., \& Lerma, M. (1990). Perception of physical attractiveness: Mechanisms involved in the maintenance of romantic relationships. Journal of Personality and Social Psychology, 59, 1192-1201.

Slotter, E. B., \& Gardner, W. L. (2011). Can you help me become the "me" I want to be? The role of goal pursuit in friendship formation. Self and Identity, 10, 231-247.

Slotter, E. B., Gardner, W. L., \& Finkel, E. J. (2010). Who am I without you? The influence of romantic breakup on the self-concept. Personality and Social Psychology Bulletin, 36, 147-160.

Smith, E. E., Adams, N., \& Schorr, D. (1978). Fact retrieval and the paradox of interference. Cognitive Psychology, 10, 438-464.

South, S. J., \& Lloyd, K. M. (1995). Spousal alternatives and marital dissolution. American Sociological Review, 21-35.

South, S. J., Trent, K., \& Shen, Y. (2001). Changing partners: Toward a macrostructuralopportunity theory of marital dissolution. Journal of Marriage and Family, 63, 743-754.

Udry, J. R. (1981). Marital alternatives and marital disruption. Journal of Marriage and the Family, 889-897.

vanDellen, M. R., \& Hoyle, R. H. (2010). Regulatory accessibility and social influences on selfcontrol. Personality and Social Psychology Bulletin, 36, 251-263. 
Weinstein, N., \& Ryan, R. M. (2010). When helping helps: autonomous motivation for prosocial behavior and its influence on well-being for the helper and recipient. Journal of Personality and Social Psychology, 98, 222-244.

Weisfeld, G. E., \& Weisfeld, C. C. (2002). Marriage: an evolutionary perspective. Neuro Endocrinology Letters, 23, 47-54.

Williamson, G. M., \& Clark, M. S. (1989). Providing help and desired relationship type as determinants of changes in moods and self-evaluations. Journal of Personality and Social Psychology, 56, 722-734.

Williamson, G. M., \& Clark, M. S. (1992). Impact of desired relationship type on affective reactions to choosing and being required to help. Personality and Social Psychology Bulletin, 18(1), 10-18.

Winczewski, L. A., Bowen, J. D., \& Collins, N. L. (2016). Is empathic accuracy enough to facilitate responsive behavior in dyadic interaction? Distinguishing ability from motivation. Psychological Science, 27(3), 394-404.

Zhang, Y., Fishbach, A., Kruglanski, A. W. (2007). The dilution model: How additional goal undermine the perceived instrumentality of a shared path. Journal of Personality and Social Psychology, 92, 389-401. 